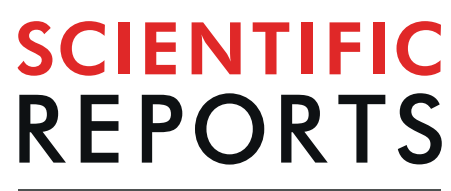

\title{
OPEN GCH1 (rs841) polymorphism in the nitric oxide-forming pathway has protective effects on obstructive sleep apnea
}

\author{
Samaneh Sheikhi Kouhsar ${ }^{1}$, Mohammadreza Bigdeli ${ }^{1,2^{*}}$, Yadollah Shakiba ${ }^{3}$ \& \\ Khosro Sadeghniiat ${ }^{4}$
}

Several studies have recently investigated the contribution of genetic factors in obstructive sleep apnea (OSA). Patients with OSA suffer from a reduction in nitric oxide (NO) serum level. This study investigated rs841, A930G p22phox, and rs1799983 polymorphisms in three critical genes involved in NO formation. A total of 94 patients with OSA and 100 healthy controls were enrolled into the study. Results showed there was no association between rs841, A930G p22phox and rs1799983 polymorphism and the risk of OSA $(P=0.51, P=0.4$ and $P=0.33$, respectively). Moreover, rs841 GA genotype had a reverse relationship with the severity of OSA $(P=0.005)$. On the other hand, rs841 GA and A930G p22phox AA genotypes had a protective effect on daytime sleepiness in OSA patients $(P=0.01$ and $P=0.02$, respectively). Additionally, the combination of rs841 and A930G p22phox (AG/AG and AG/AA) genotypes was significantly associated with a reduction in daytime sleepiness in OSA patients $(P=0.03$ and $P=0.03$, respectively). According to the results of our study, GA genotype of rs 841 and GA/AA genotypes of A930G p22phox polymorphisms significantly reduced the severity of the problem and daytime sleepiness in OSA patients.

Obstructive sleep apnea (OSA) is a common sleep disorder ${ }^{1,2}$, which is characterized by repetitive pharyngeal obstruction, leading to apnea and hypopnea during sleep ${ }^{3}$. Headache, Fatigue, excessive daytime sleepiness, non-refreshing sleep, irritability, and decreased cognitive functions are the common symptoms of OSA ${ }^{4,5}$. The prevalence of undiagnosed OSA among the general population is estimated to be $5 \%$. In addition, the prevalence of undiagnosed moderate to severe OSA among a sample of general population in Western Australia was $9 \%$. Nonetheless, it is estimated that only $40 \%$ of people with OSA are diagnosed ${ }^{6,7}$. Untreated OSA is associated with different health complications, including metabolic disorder ${ }^{8}$, cognitive impairment $^{9}$, depression ${ }^{10}$, and cardiovascular diseases ${ }^{11}$; this disorder also has an economic burden on community ${ }^{12}$. OSA is a multifactorial disorder and several genetic studies have provided evidence for the possible association between OSA and genetic factors ${ }^{13,14}$.

Nitric Oxide (NO) is synthesized from L-Arginine substrate by a family of nitric oxide synthase (NOS) enzymes. In this process, $\mathrm{NADPH}$ and $\mathrm{O}_{2}$ serve as co-substrates and 6-tetrahydrobiopterin (BH4) acts as a co-factor ${ }^{15}$. NO is a signaling molecule in the human body that is involved in many physiological and pathological processes $^{16,17}$. NO plays an important role in neural signaling, immune response, vasodilation, and modulating insulin sensitivity ${ }^{18}$. NO deficiency is involved in the pathogenesis of multiple diseases such as hypertension ${ }^{19}$, diabetes mellitus ${ }^{20}$, stroke ${ }^{21}$, and OSA ${ }^{22}$. Nitric Oxide derivatives (serum nitrites and nitrates) and L-Arginine plasma levels decrease in patients with OSA, however, they increase after continuous positive airway pressure (CPAP) therapy ${ }^{23,24}$. Chronic sleep deprivation and repetitive hypoxia / reoxygenation in patients with OSA impairs endothelial function through reducing NO bioavailability and increasing oxidative stress and inflammation $^{11}$. Therefore, changes in substrate, enzymes, and co-factors that are involved in NO formation may decrease NO levels in patients with OSA. Several functional polymorphisms have been identified in NO-forming

${ }^{1}$ Department of Animal Sciences and Biotechnology, Faculty of Life Sciences and Biotechnology, Shahid Beheshti University, Tehran, Iran. ${ }^{2}$ Institute for Cognitive and Brain Sciences, Shahid Beheshti University, Tehran, Iran. ${ }^{3}$ Regenerative Medicine Research Center, Kermanshah University of Medical Sciences, Kermanshah, Iran. ${ }^{4}$ Occupational Sleep Research Center, Baharloo Hospital, Tehran, Iran. *email: bigdelimohammadreza@yahoo.com 


\begin{tabular}{|l|l|l|l|}
\hline Characteristics & Control N= 100 & Patient N=94 & Pvalue \\
\hline Men n (\%) & $79(79 \%)$ & $75(80 \%)$ & 0.89 \\
\hline Age & $42.74 \pm 7.76$ & $44.3 \pm 11.45$ & 0.26 \\
\hline BMI & $26.77 \pm 3.9$ & $29.14 \pm 4.5$ & 0.000 \\
\hline STOP-BANG & $1.2 \pm 0.55$ & $3.85 \pm 1.45$ & 0.000 \\
\hline ESS & $1.3 \pm 1.56$ & $9.42 \pm 6.00$ & 0.000 \\
\hline
\end{tabular}

Table 1. Characteristics of patient and control groups. BMI: Body Mass Index, ESS: Epworth Sleep Scale. Characteristics are defined by Mean \pm Standard Deviation.

pathway ${ }^{25,26}$. eNOS is encoded by NO3 gene, and some polymorphisms have been reported for NOS3 gene, including rs1799983, intron 4a/b, rs2070744, etc. They play a role in different diseases such as OSA ${ }^{27,28}$. According to previous studies, G894 T (rs1799983) variant is responsible for NO reduction ${ }^{29}$.

GTP cyclohydrolase $1(\mathrm{GCH} 1)$ catalyzes the biosynthesis of $\mathrm{BH} 4$ that is an essential cofactor in the synthesis of NO. Moreover, rs841 polymorphism of GCH1 is involved in neuropathic pain, attention, and stroke $\mathrm{e}^{30-32}$. So far, no study has investigated the association between this polymorphism and OSA. NADPH oxidase is another factor which is involved in NO formation and is identified as the major source of reactive oxygen species (ROS). It is a multicomponent enzyme consisting of catalytic subunits and cytosolic proteins. Among catalytic subunits, p22phox is a physical conduct for transferring electrons across the membrane and is critical for the enzymatic activity. On the other hand, p22phox subunit polymorphism is identified as a factor involved in OSA and cardiovascular diseases $^{33,34}$.

This study investigated the association between OSA and rs841(G > A) in GTP cyclohydrolase I (GCH1), A930G p22phox ( $\mathrm{G}>\mathrm{A}$ ) in NADPH Oxidase, and rs1799983 (G>T) in eNOS polymorphisms.

To the best of our knowledge, this study is the first research investigating the association between GCH1 polymorphism and OSA, as well as the relationship between rs841, A930G p22phox, and 1799983 in Iranian people.

\section{Results}

Genotypes, allele frequencies, and risk of OSA. Table 1 presents the data collected on patients' and controls' age, gender, BMI, and the data collected via STOP-BANG and Epworth Sleep Scale questionnaires. The collected data were used to assess the association between three polymorphisms in three different genes and the risk of OSA. All genotypes observed in cases and controls were consistent with Hardy-Weinberg equilibrium (HWE) $(P>0.05)$. Table 2 presents the genotype distributions and allele frequencies of rs841(GCH1), A930G p22phox (NADPH Oxidase), and rs1799983 (eNOS) polymorphisms. Based on the results, genotypes and allele frequencies of rs841 (G>A), A930G p22phox $(\mathrm{G}>\mathrm{A})$ and $\mathrm{rs} 1799983(\mathrm{G}>\mathrm{T})$ polymorphisms had no significant association with the risk of OSA (A vs. G: $\mathrm{OR}=0.74,95 \% \mathrm{CI}=0.3-1.81 ; P=0.51, \mathrm{~A} v s$. G: $\mathrm{OR}=0.82,95 \%$ $\mathrm{CI}=0.53-1.28 ; P=0.4$ and $\mathrm{T} v s . \mathrm{G}: \mathrm{OR}=2.12,95 \% \mathrm{CI}=0.46-9.74 ; P=0.33$, respectively).

Genotypes and severity of OSA. In order to conduct further assessment, we divided OSA patients into two groups. There were 43 patients in severe group and 51 patients in mild-to-moderate group. Table 1 in appendix presents the polysomnographic parameters in patients. Statistical analysis did not show a significant difference between the severe and non-severe OSA patients in terms of the genotypes distribution of A930G p22phox (NADPH Oxidase) and rs1799983 (eNOS) polymorphism $(P>0.05$, Table 3). Interestingly, as shown in Table 3, for the first time we found a significant difference between the severe and mild-to-moderate OSA patients in terms of the genotype of rs841 (GCH1), where GA genotype was more frequently observed in the mild-to-moderate $\mathrm{OSA}$ patients (Crude $\mathrm{OR}=0.3,95 \% \mathrm{CI}=0.12-0.78 ; P=0.01$, after adjusting for age, gender, $\mathrm{BMI}, \mathrm{OR}=0.21,95 \% \mathrm{CI}=0.07-0.62 ; P=0.005)$. The results showed that GA genotype of rs841 $(\mathrm{GCH} 1)$ reduced the severity of OSA in patients; moreover, this genotype of rs841 had a protective effect in patients with OSA.

Genotypes and daytime sleepiness in OSA. We investigated the association between the three genetic polymorphisms involved in NO formation and daytime sleepiness in OSA patients. We divided patients into two groups, patients with daytime sleepiness $(n=72)$ and patients without daytime sleepiness $(n=22)($ Table 4$)$. Assessing rs841 (GCH1), the frequency of GA genotype was significantly higher in patients without daytime sleepiness, as compared with patients with daytime sleepiness (Crude $\mathrm{OR}=0.27,95 \% \mathrm{CI}=0.1-0.8 ; P=0.01$, after adjustment for age, gender, $\mathrm{BMI} O \mathrm{OR}=0.23,95 \% \mathrm{CI}=0.07-0.7 ; P=0.01)$. Furthermore, assessing A930G p22phox, there was a significant difference between the patients without daytime sleepiness and the patients with daytime sleepiness in terms of genotype distribution; according to the results, AA genotype decreased daytime sleepiness in patients and had a protective effect (Crude $\mathrm{OR}=0.23,95 \% \mathrm{CI}=0.06-0.95 ; P=0.04$, after adjustment for age, gender, $\mathrm{BMI} \mathrm{OR}=0.14,95 \% \mathrm{CI}=0.02-0.8 ; P=0.02)$. There was no association between $\mathrm{rs} 179983$ (eNOS) genotypes and daytime sleepiness in the two groups of patients $(P>0.05)$.

Association between genotype combinations and daytime sleepiness in OSA patients. Interactions between polymorphisms within genes involved in the reduction of daytime sleepiness in OSA patients were investigated using the logistic regression analysis and the results showed a significant relationship between rs841 and A930G p22phox in two genotypes combination (Crude $\mathrm{OR}=0.16,95 \% \mathrm{CI}=0.02-0.98 ; P=0.04$ and Crude $\mathrm{OR}=0.09,95 \%$ $\mathrm{CI}=0.009-0.97 ; P=0.04$, after adjustment for age, gender, $\mathrm{BMI} \mathrm{OR}=0.11,95 \% \mathrm{CI}=0.01-0.8 ; P=0.03$ and $\mathrm{OR}=0.05$, $95 \% \mathrm{CI}=0.003-0.83 ; P=0.03$, respectively). The combinations of rs841 GA genotype and A930G p22phox GA/AA 


\begin{tabular}{|c|c|c|c|c|c|c|c|}
\hline \multirow[b]{2}{*}{ SNP } & \multirow{2}{*}{$\begin{array}{l}\text { Genotype/ } \\
\text { Allele }\end{array}$} & \multirow{2}{*}{\begin{tabular}{|l|} 
Control \\
$\mathrm{N}=100$ \\
\end{tabular}} & \multirow{2}{*}{\begin{tabular}{|l|} 
OSA \\
$\mathrm{N}=94$ \\
\end{tabular}} & \multirow{2}{*}{\begin{tabular}{|l|} 
Crude OR \\
$(95 \%$ CI $)$ \\
\end{tabular}} & \multirow[b]{2}{*}{ Pvalue } & \multirow{2}{*}{\begin{tabular}{|l|} 
Adjusted OR \\
$(95 \% \mathrm{CI})$
\end{tabular}} & \multirow[b]{2}{*}{ P value } \\
\hline & & & & & & & \\
\hline \multirow[t]{11}{*}{ Rs841 } & GG & $63(63 \%)$ & $59(62.8 \%)$ & 1.00 (Reference) & & & \\
\hline & GA & $33(33 \%)$ & $32(34 \%)$ & $1.03(0.55-1.92)$ & 0.9 & $1.64(0.3-8.79)$ & 0.56 \\
\hline & AA & $4(4 \%)$ & $3(3.2 \%)$ & $0.8(0.19-3.09)$ & 0.77 & $1.59(0.28-8.83)$ & 0.59 \\
\hline & Dominant & & & & & & \\
\hline & GG & $63(63 \%)$ & $59(62.8 \%)$ & 1.00 (Reference) & & & \\
\hline & $\mathrm{GA}+\mathrm{AA}$ & $37(37 \%)$ & $35(37.2 \%)$ & $1.01(0.56-1.79)$ & 0.97 & $0.93(0.5-1.71)$ & 0.82 \\
\hline & Recessive & & & & & & \\
\hline & $\mathrm{GG}+\mathrm{GA}$ & $96(96 \%)$ & $91(96.8 \%)$ & 1.00 (Reference) & & & \\
\hline & AA & $4(4 \%)$ & $3(3.2 \%)$ & $0.79(0.19-3.01)$ & 0.76 & $0.61(0.11-3.25)$ & 0.56 \\
\hline & G & $159(79.5 \%)$ & $150(79.8 \%)$ & 1.00 (Reference) & & & \\
\hline & $\mathrm{A}$ & $41(20.5 \%)$ & $38(20.2 \%)$ & $0.98(0.6-1.58)$ & 0.94 & $0.74(0.3-1.81)$ & 0.51 \\
\hline \multirow{11}{*}{ A930G p22phox } & GG & $29(29 \%)$ & $27(28.7 \%)$ & 1.00 (Reference) & & & \\
\hline & GA & $48(48 \%)$ & $53(56.4 \%)$ & $1.18(0.6-2.33)$ & 0.6 & $1.18(0.6-2.32)$ & 0.63 \\
\hline & AA & $23(23 \%)$ & $14(14.9 \%)$ & $0.65(0.26-1.43)$ & 0.32 & $0.68(0.28-1.68)$ & 0.41 \\
\hline & Dominant & & & & & & \\
\hline & GG & $29(29 \%)$ & $27(28.7 \%)$ & 1.00 (Reference) & & & \\
\hline & $\mathrm{GA}+\mathrm{AA}$ & $71(71 \%)$ & $67(81.3 \%)$ & $1.01(0.55-1.86)$ & 0.96 & $1.03(0.54-1.97)$ & 0.92 \\
\hline & Recessive & & & & & & \\
\hline & $\mathrm{GG}+\mathrm{GA}$ & $77(77 \%)$ & $80(85.1 \%)$ & 1.00 (Reference) & & & \\
\hline & AA & $23(23 \%)$ & $14(14.9 \%)$ & $0.58(0.28-1.23)$ & 0.15 & $0.61(0.28-1.34)$ & 0.22 \\
\hline & G & $106(53 \%)$ & $107(57 \%)$ & 1.00 (Reference) & & & \\
\hline & $\mathrm{A}$ & $94(47 \%)$ & $81(43 \%)$ & $0.85(0.57-1.26)$ & 0.43 & $0.82(0.53-1.28)$ & 0.4 \\
\hline \multirow{11}{*}{ Rs1799983 } & GG & $69(69 \%)$ & $51(54.2 \%)$ & 1.00 (Reference) & & & \\
\hline & GT & $28(28 \%)$ & $37(39.4 \%)$ & $1.78(0.96-3.24)$ & 0.06 & $1.55(0.82-2.93)$ & 0.17 \\
\hline & TT & $3(3 \%)$ & $6(6.4 \%)$ & $2.7(0.71-10.17)$ & 0.15 & $\begin{array}{l}3.57(0.82- \\
15.48)\end{array}$ & 0.08 \\
\hline & Dominant & & & & & & \\
\hline & GG & $69(69 \%)$ & 51 (54.2\%) & 1.00 (Reference) & & & \\
\hline & GT+TT & $31(31 \%)$ & $45(45.8 \%)$ & $1.96(1.11-3.55)$ & 0.02 & $3.17(0.07-1.14)$ & 0.93 \\
\hline & Recessive & & & & & & \\
\hline & GG + GT & $97(97 \%)$ & $88(83.6 \%)$ & 1.00 (Reference) & & & \\
\hline & \begin{tabular}{|l|} 
TT \\
\end{tabular} & $3(3 \%)$ & $6(6.4 \%)$ & $2.2(0.57-8.2)$ & 0.26 & $0.32(0.07-1.37)$ & 0.12 \\
\hline & G & $166(83 \%)$ & $139(74 \%)$ & 1.00 (Reference) & & & \\
\hline & $\mathrm{T}$ & $34(17 \%)$ & $49(26 \%)$ & $1.72(1.04-2.81)$ & 0.02 & $2.12(0.46-9.74)$ & 0.33 \\
\hline
\end{tabular}

Table 2. Genotype distribution and allele frequency in OSA and controls. SNP: Single Nucleotide Polymorphism, OSA: Obstructive Sleep Apnea, OR: Odd Ratio, CI: Confidence Interval. Adjusted odds ratio were adjusted for body mass index.

genotype were significantly associated with a reduction in daytime sleepiness in patients with OSA, as compared with the reference combination of rs841 GG and A930G p22phox GG genotype (Table 5). The combinations of other genotypes did not result in a significant difference $(P>0.05)$.

\section{Discussion}

Over the past two decades, public awareness about the importance of sleep and its related disorders has increased significantly ${ }^{35}$. In this work, we investigated the association between the susceptibility to OSA and GCH1 (rs841), NADPH oxidase (A930G p22phox (CYBA)) and endothelial NOS (rs1799983) polymorphisms. These genes play a role in nitric oxide formation ${ }^{36}$. To our knowledge, this was the first study that assessed the association between rs841 (GCH1) polymorphism and the risk of OSA. Some studies have shown that rs 841 polymorphism is associated with the risk of ischemic stroke, endothelial dysfunction, and oxidative stress in patients with type 2 diabetes mellitus ${ }^{32,37}$. Interestingly, our results indicated no association between rs841 and the susceptibility to OSA; on the contrary, GA genotype of this polymorphism reduced the severity of the disease and daytime sleepiness in patients with OSA. Moreover, we did not find any relationship between A930G p22phox polymorphism and the risk of OSA; however, according to the results of a study by Pierola et al., this polymorphism plays an important role in genetic susceptibility to OSA ${ }^{33}$. In contrast, AA genotype of A930G p22phox polymorphism prevented daytime sleepiness in patients with OSA. The analysis of data collected in our study showed that $\mathrm{T}$ allele of rs 1799983 polymorphism was not associated with increased risk of OSA. Bayazit et. al's study showed that eNOS4 polymorphism was not associated with OSA, while eNOS296 polymorphism was associated with OSA susceptibility. In this study, there was no relationship between eNOS4, eNOS296 polymorphisms and polysomnography 


\begin{tabular}{|c|c|c|c|c|c|c|c|}
\hline \multirow[b]{2}{*}{ SNP } & \multirow[b]{2}{*}{ Genotype } & \multirow{2}{*}{\begin{tabular}{|l|} 
Non-severe \\
$\mathrm{N}=\mathbf{5 1}$ \\
\end{tabular}} & \multirow{2}{*}{\begin{tabular}{|l|} 
Severe \\
$\mathrm{N}=43$
\end{tabular}} & \multirow[b]{2}{*}{ Crude OR } & \multirow[b]{2}{*}{ P value } & \multirow{2}{*}{\begin{tabular}{|l|} 
Adjusted OR \\
$(95 \% \mathrm{CI})$ \\
\end{tabular}} & \multirow{2}{*}{$\begin{array}{l}P \\
\text { value }\end{array}$} \\
\hline & & & & & & & \\
\hline \multirow{3}{*}{ Rs841 } & GG & 26 & 33 & 1.00 (Reference) & & & \\
\hline & GA & 23 & 9 & $0.3(0.12-0.78)$ & 0.01 & $0.21(0.07-0.62)$ & 0.005 \\
\hline & AA & 2 & 1 & $0.3(0.02-3.58)$ & 0.44 & $0.05(0.002-1.32)$ & 0.07 \\
\hline \multirow{3}{*}{ A930G p22phox } & GG & 14 & 13 & 1.00 (Reference) & & & \\
\hline & GA & 31 & 22 & $0.76(0.3-1.92)$ & 0.57 & $0.61(0.22-1.7)$ & 0.35 \\
\hline & AA & 6 & 8 & $1.43(0.38-4.7)$ & 0.58 & $1.14(0.27-4.84)$ & 0.85 \\
\hline \multirow{3}{*}{ Rs1799983 } & GG & 28 & 23 & 1.00 (Reference) & & & \\
\hline & GT & 18 & 19 & $1.28(0.55-3.03)$ & 0.56 & $0.92(0.36-2.31)$ & 0.86 \\
\hline & TT & 5 & 1 & $0.24(0.01-2.11)$ & 0.18 & $0.33(0.33-3.36)$ & 0.35 \\
\hline
\end{tabular}

Table 3. Association between rs841, A930G p22phox, rs1799983 genotypes and the severity of OSA. SNP: Single Nucleotide Polymorphism, OSA: Obstructive Sleep Apnea, OR: Odd Ratio, CI: Confidence Interval. Adjusted odds ratio were adjusted for age, gender and body mass index.

\begin{tabular}{|c|c|c|c|c|c|c|c|}
\hline \multirow[b]{2}{*}{ SNP } & \multirow[b]{2}{*}{ Genotype } & \multirow{2}{*}{\begin{tabular}{|l|} 
Non-sleepy \\
$\mathbf{N}=\mathbf{2 2}$ \\
\end{tabular}} & \multirow{2}{*}{$\begin{array}{l}\text { Sleepy } \\
N=72\end{array}$} & \multirow{2}{*}{\begin{tabular}{|l|} 
Crude OR \\
$(95 \% \mathrm{CI})$ \\
\end{tabular}} & \multirow[b]{2}{*}{ P value } & \multirow{2}{*}{\begin{tabular}{|l|} 
Adjusted OR \\
$(95 \% \mathrm{CI})$ \\
\end{tabular}} & \multirow[b]{2}{*}{$P$ value } \\
\hline & & & & & & & \\
\hline \multirow[t]{3}{*}{ Rs841 } & GG & $9(40.9 \%)$ & $51(70.8 \%)$ & 1.00 (Reference) & & & \\
\hline & GA & $12(54.5 \%)$ & $19(26.4 \%)$ & $0.27(0.1-0.8)$ & 0.01 & $0.23(0.07-0.7)$ & 0.01 \\
\hline & $\mathrm{AA}$ & $1(4.5 \%)$ & $2(2.8 \%)$ & $0.35(0.03-5.64)$ & 0.39 & $0.3(0.01-5.08)$ & 0.4 \\
\hline \multirow[t]{3}{*}{ A930G p22phox } & GG & $4(18.2 \%)$ & $23(31.9 \%)$ & 1.00 (Reference) & & & \\
\hline & GA & $12(54.5 \%)$ & $41(56.9 \%)$ & $0.59(0.19-1.99)$ & 0.4 & $0.56(0.15-2.07)$ & 0.38 \\
\hline & AA & $6(27.3 \%)$ & $8(11.2 \%)$ & $0.23(0.06-0.95)$ & 0.04 & $0.14(0.02-0.8)$ & 0.02 \\
\hline \multirow[t]{3}{*}{ Rs1799983 } & GG & $14(63.63 \%)$ & $37(51.4 \%)$ & 1.00 (Reference) & & & \\
\hline & GT & $6(27.27 \%)$ & $31(43 \%)$ & $1.95(0.66-5.81)$ & 0.21 & $1.79(0.58-5.52)$ & 0.3 \\
\hline & TT & $2(9 \%)$ & $4(5.6 \%)$ & $0.75(0.16-4.34)$ & 0.76 & $\begin{array}{l}1.61(0.23- \\
11.03)\end{array}$ & 0.62 \\
\hline
\end{tabular}

Table 4. Association between rs841, A930G p22phox, rs1799983 genotype and daytime sleepiness in OSA. SNP: Single Nucleotide Polymorphism, OSA: Obstructive Sleep Apnea, OR: Odd Ratio, CI: Confidence Interval. Adjusted odds ratio were adjusted for age, gender and body mass index.

\begin{tabular}{|l|l|l|l|l|l|l|l|}
\hline Genotype & & & & & & \\
\cline { 1 - 7 } rs841 & A930G & Non-sleepy & Sleepy & Crude OR (95\% CI) & P value & Adjusted OR (95\% CI) & P value \\
\hline GA & GA & 7 & 8 & $0.16(0.02-0.98)$ & 0.04 & $0.11(0.01-0.8)$ & 0.03 \\
\hline GA & AA & 3 & 2 & $0.09(0.009-0.97)$ & 0.04 & $0.05(0.003-0.83)$ & 0.03 \\
\hline
\end{tabular}

Table 5. Distribution of combined genotypes in sleep and non-sleep OSA. OR: Odd Ratio, CI: Confidence Interval. Adjusted odds ratio were adjusted for age, gender and body mass index.

parameters, diabetes mellitus, coronary artery disease, arrhythmia, hypertension, hypercholesterolemia, and smoking $^{28}$. NO reduces in OSA patients, treatment with CPAP ameliorate endothelial nitric oxide release and vasodilation $^{38}$.

Several studies have indicated a reduction in nitric oxide bioavailability in OSA patients ${ }^{3,39,40}$. BH4 is an essential co-factor required for the activation of all the three nitric oxide synthases; changes in this co-factor can affect NO formation ${ }^{41}$. GTP Cyclohydrolas $1(\mathrm{GCH} 1)$ is a rate-limiting enzyme in the $\mathrm{BH} 4$ synthesis ${ }^{42}$. Therefore, changes in $\mathrm{GCH} 1$ gene could decrease or increase $\mathrm{BH} 4$ availability for NOS. Some studies have demonstrated that GCH1 rs841 polymorphism has a similar effect on BH4 levels in plasma and vascular tissues, and acts as a pain-protective haplotype of $\mathrm{GCH} 1^{43}$. This polymorphism reduces $\mathrm{BH} 4$ levels in people with cardiovascular diseases, results in a reduction in NO, and increase superoxide production ${ }^{42}$. Given the protective effect of this polymorphism and other haplotypes of GCH1, it could be concluded that rs 841 moderately reduces $\mathrm{GCH} 1$ expression and $\mathrm{BH} 4$ production ${ }^{44}$. Cycles of intermittent hypoxia, as a sign of OSA, promote oxidative stress and enhance the production of reactive oxygen species ${ }^{39}$. NADPH oxidase is a membrane-bound complex enzyme with cytosolic subunits (Rac, p47phox, p67phox) that are linked to catalytic membrane subunits (Nox, p22phox) to facilitate the superoxide production ${ }^{45}$. P22phox subunit plays an important role in the normal function of enzymes ${ }^{46}$. Recent studies have demonstrated that several polymorphisms of p22phox gene (CYBA) are associated with increased oxidative stress and cardiovascular diseases ${ }^{32,47,48}$. According to Pierola et al., patients with GA and GG genotypes of A930G p22phox polymorphism are more at risk of OSA. A930G p22phox polymorphism changes the expression of $\mathrm{p} 22$ phox, in addition $\mathrm{G}$ allele increases p22phox expression and oxidative stress. A-930G polymorphism is associated with sleep apnea independently of sympathetic activation, obesity, hypertension, hyperlipidemia and 
diabetes mellitus ${ }^{33}$. A meta-analysis study indicated that A930G polymorphism might be a protective factor for hypertension ${ }^{49}$. Based on another study, NO production is lower in hypertensive patients with GG genotype of A930G polymorphism ${ }^{46}$, that could indicate that patients with GA/AA genotype produce more NO than patients with GG genotype; this phenomenon may justify the protective effect of GA/AA genotype in OSA patients. eNOS is one of the three isoforms of NOS enzyme that produces nitric oxide in the presence of BH4 and NADPH ${ }^{15}$. eNOS and NO play an important role in the regulation of endothelial vasodilation, and their functional impairment plays an important role in the development of various disease ${ }^{50}$, such as cardiovascular diseases ${ }^{51}$, cerebral ischemia ${ }^{52}$, and OSA ${ }^{53}$. Therefore, the expression of eNOS and subsequent endothelial NO release may be affected by gene polymorphism ${ }^{54}$. A study investigated 50 single nucleotide polymorphisms of eNOS in children with OSA and the results suggested that these polymorphisms could contribute to the risk of OSA-induced cardiovascular morbidity ${ }^{55}$. G894T (rs1799983) polymorphism of eNOS is a functional polymorphism which could lead to the sequence change in Glu 298 Asp $^{56}$. Moreover, rs1799983 polymorphism of eNOS gene is associated with reduced activity of NOS and bioavailability of NO. Concurrent presence of CETP B1, NOS3 T, and ANGPTL8 T alleles increases the risk of cardiovascular diseases and type 2 diabetes mellitus ${ }^{57}$.

This study had some limitations. Firstly, the genes selected for investigation had overlap with other diseases such as cardiovascular diseases, diabetes, stroke, and brain ischemia; thus, we only selected patients with no comorbidity. Therefore, it had an advantage and a disadvantage for our study. As an advantage, the genetic assessments were just performed for people who only had OSA; however, as a disadvantage, it was difficult to find patients with no comorbidity, and it resulted in a small sample size. Hence, it is suggested to conduct further studies with larger sample sizes. On the other hand, in order to perform a comparative analysis, it is better to select another group of OSA patients with a concurrent comorbidity. Secondly, we assessed just one polymorphism in each gene, hence the association between other polymorphisms and OSA could be investigated further.

Overall, our study showed that gene polymorphisms in nitric oxide-forming pathway had a reverse association with OSA. rs841 and A930G p22phox polymorphisms had a protective effect in patients with OSA.

\section{Materials and Methods}

Subjects. This study, as a case-control study, was performed in Baharloo Hospital and Imam Khomeini Hospital, Tehran, Iran. The study protocol was approved by Ethics Committee of Tehran University of Medical Sciences (ethical code: IR.TUMS.VCR.REC.1395.1107). A written informed consent was obtained from all the participants. The experiments were performed in accordance with the American Academy of Sleep Medicine Guidelines ${ }^{58}$.

A total of 94 patients (F19: M75) with OSA and 100 healthy controls (F21: M79) were matched in terms of age and gender. The data on personal characteristics, medical history, and sleep information were obtained through using a questionnaire. All the patients underwent a polysomnography test. Polysomnography was performed overnight, and it monitored many body functions, including skeletal muscle activation (EMG), eye movement (EOG), brain activity (EEG), blood pressure, heart beating, and oxygen saturation. After test analysis, people with $5 \leq \mathrm{AHI}<15,15 \leq \mathrm{AHI}<30$ and $\mathrm{AHI} \geq 30$ were classified into the three groups of patients with mild, moderate, and severe OSA, respectively.

In order to control the costs and consider practical issues, polysomnography was not performed for the controls, and the controls were considered healthy on the basis of data on history that were obtained via answering STOP-BANG and Epworth Sleepiness Scale questionnaires. The cutoff point for STOP-BANG questionnaire was $2^{59}$, and the cutoff point for Epworth Sleepiness Scale questionnaire was $10^{60}$.

Exclusion criteria for both case and control groups were the presence of trauma, inflammatory diseases, cardiovascular diseases, brain ischemia, diabetes, chronic pulmonary disorders, asthma, chronic kidney disease, thyroid diseases, smoking history, and drug addiction. Blood samples were collected from the members in the two groups and stored in $-20^{\circ} \mathrm{C}$ to be used for further examinations.

DNA extraction and genotyping. DNA was extracted from the whole peripheral blood samples using Geneall DNA extraction kit (Geneall, Seoul, South Korea), in accordance with the manufacturer's protocol. NADPH Oxidase A930G p22phox was genotyped via Restricted Fragment Length Polymorphism (RFLP) method. The polymerase chain reaction (PCR) forward primer was 5' GGAAACCACCAAGTGCCTCGGATGG $3^{\prime}$ and Revers primer was $5^{\prime}$ TCTGCACCCTGATGCTACCAAGGAC $3^{\prime}$. PCR was carried out using a volume of $30 \mathrm{ml}$, under the following condition: an initial denaturation step at $94^{\circ} \mathrm{C}$ for $1 \mathrm{~min}$, followed by 31 cycles of $1 \mathrm{~min}$ at $94^{\circ} \mathrm{C}, 1 \mathrm{~min}$ at $67^{\circ} \mathrm{C}$, and $1 \mathrm{~min}$ at $72^{\circ} \mathrm{C}$; finally, the last elongation step was performed at $72^{\circ} \mathrm{C}$ for $2 \mathrm{~min}$. Amplified products were digested using h $3 \mathrm{U}$ of BbvI restriction enzyme for $1 \mathrm{~h}$ at $37^{\circ} \mathrm{C}$ (New England Biolabs, Beverly, MA, USA). The results of digestion were separated on 3\% agarose (Sigma-Aldrich, USA). TaqMan SNP genotyping assays were used for GCH1 rs841 and eNOS rs1799983 genotyping. Following the manufacturer's protocol, the probes were designed by Applied Biosystems and genotyping were performed on Step-One Plus Real-Time PCR system (Applied Biosystems, Foster City, California, United States).

Statistical analysis. Statistical analyses were performed in SPSS 25.0 software package for Windows (SPSS Inc, Chicago, IL, USA) and GraphPad Prism 8 (GraphPad Software, San Diego, CA). Chi-square test was preformed to assess deviation from Hardy-Weinberg equilibrium to assess genotypes distribution. The effect of each single-nucleotide polymorphism (SNP) on OSA was investigated using multiple logistic regression analysis adjusted for body mass index in the patients and controls, however, in order to analyze the data obtained from the patient group, multiple logistic regression was preformed after adjusting for age, gender, and body mass index. The strength of the association between the three polymorphisms and OSA was measured via computing ORs at a confidence interval of $95 \%$. Statistical significance was defined as a two-tailed $P<0.05$. 
Received: 2 August 2019; Accepted: 26 November 2019;

Published online: 09 December 2019

\section{References}

1. Peppard, P. E. et al. Increased prevalence of sleep-disordered breathing in adults. Am J Epidemiol 177, 1006-1014, https://doi. org/10.1093/aje/kws342 (2013).

2. Qaseem, A. et al. Management of obstructive sleep apnea in adults: A clinical practice guideline from the American College of Physicians. Ann Intern Med 159, 471-483, https://doi.org/10.7326/0003-4819-159-7-201310010-00704 (2013).

3. Lavie, L. Obstructive sleep apnoea syndrome-an oxidative stress disorder. Sleep Med Rev 7, 35-51 (2003).

4. Osman, A. M., Carter, S. G., Carberry, J. C. \& Eckert, D. J. Obstructive sleep apnea: current perspectives. Nat Sci Sleep 10, 21-34, https://doi.org/10.2147/NSS.S124657 (2018).

5. Romero, E., Krakow, B., Haynes, P. \& Ulibarri, V. Nocturia and snoring: predictive symptoms for obstructive sleep apnea. Sleep Breath 14, 337-343, https://doi.org/10.1007/s11325-009-0310-2 (2010).

6. Simpson, L. et al. High prevalence of undiagnosed obstructive sleep apnoea in the general population and methods for screening for representative controls. Sleep Breath 17, 967-973, https://doi.org/10.1007/s11325-012-0785-0 (2013).

7. Knauert, M., Naik, S., Gillespie, M. B. \& Kryger, M. Clinical consequences and economic costs of untreated obstructive sleep apnea syndrome. World J Otorhinolaryngol Head Neck Surg 1, 17-27, https://doi.org/10.1016/j.wjorl.2015.08.001 (2015).

8. Bonsignore, M. R., Borel, A. L., Machan, E. \& Grunstein, R. Sleep apnoea and metabolic dysfunction. Eur Respir Rev 22, 353-364, https://doi.org/10.1183/09059180.00003413 (2013).

9. Lim, D. C. \& Pack, A. I. Obstructive sleep apnea and cognitive impairment: addressing the blood-brain barrier. Sleep Med Rev 18, 35-48, https://doi.org/10.1016/j.smrv.2012.12.003 (2014).

10. Jehan, S. et al. Depression, Obstructive Sleep Apnea and Psychosocial Health. Sleep Med Disord 1 (2017)

11. Eisele, H. J., Markart, P. \& Schulz, R. Obstructive Sleep Apnea, Oxidative Stress, and Cardiovascular Disease: Evidence from Human Studies. Oxid Med Cell Longev 2015, 608438, https://doi.org/10.1155/2015/608438 (2015).

12. Kapur, V. K. Obstructive sleep apnea: diagnosis, epidemiology, and economics. Respir Care 55, 1155-1167 (2010).

13. Casale, M. et al. Obstructive sleep apnea syndrome: from phenotype to genetic basis. Curr Genomics 10, 119-126, https://doi. org/10.2174/138920209787846998 (2009).

14. Mukherjee, S., Saxena, R. \& Palmer, L. J. The genetics of obstructive sleep apnoea. Respirology 23, 18-27, https://doi.org/10.1111/ resp.13212 (2018)

15. Stuehr, D. J. Enzymes of the L-arginine to nitric oxide pathway. J Nutr 134, 2748S-2751S; discussion 2765S-2767S, https://doi. org/10.1093/jn/134.10.2748S (2004).

16. Hou, Y. C., Janczuk, A. \& Wang, P. G. Current trends in the development of nitric oxide donors. Curr Pharm Des 5, 417-441 (1999).

17. Tuteja, N., Chandra, M., Tuteja, R. \& Misra, M. K. Nitric Oxide as a Unique Bioactive Signaling Messenger in Physiology and Pathophysiology. J Biomed Biotechnol 2004, 227-237, https://doi.org/10.1155/S1110724304402034 (2004).

18. Levine, A. B., Punihaole, D. \& Levine, T. B. Characterization of the role of nitric oxide and its clinical applications. Cardiology 122, 55-68, https://doi.org/10.1159/000338150 (2012).

19. Hermann, M., Flammer, A. \& Luscher, T. F. Nitric oxide in hypertension. J Clin Hypertens (Greenwich) 8, 17-29 (2006).

20. Tessari, P. et al. Nitric oxide synthesis is reduced in subjects with type 2 diabetes and nephropathy. Diabetes 59, 2152-2159, https:// doi.org/10.2337/db09-1772 (2010).

21. Chen, Z. Q., Mou, R. T., Feng, D. X., Wang, Z. \& Chen, G. The role of nitric oxide in stroke. Med Gas Res 7, 194-203, https://doi. org/10.4103/2045-9912.215750 (2017)

22. Haight, J. S. \& Djupesland, P. G. Nitric oxide (NO) and obstructive sleep apnea (OSA). Sleep Breath 7, 53-62, https://doi.org/10.1007/ s11325-003-0053-4 (2003).

23. Lavie, L., Hefetz, A., Luboshitzky, R. \& Lavie, P. Plasma levels of nitric oxide and L-arginine in sleep apnea patients: effects of nCPAP treatment. J Mol Neurosci 21, 57-63, https://doi.org/10.1385/JMN:21:1:57 (2003).

24. Ip, M. S. et al. Circulating nitric oxide is suppressed in obstructive sleep apnea and is reversed by nasal continuous positive airway pressure. Am J Respir Crit Care Med 162, 2166-2171, https://doi.org/10.1164/ajrccm.162.6.2002126 (2000).

25. Devendran, A. et al. Allele, Genotype and Haplotype Structures of Functional Polymorphic Variants in Endothelial Nitric Oxide Synthase (eNOS), Angiotensinogen (ACE) and Aldosterone Synthase (CYP11B2) Genes in Healthy Pregnant Women of Indian Ethnicity. J Reprod Infertil 16, 180-192 (2015).

26. Niu, W. \& Qi, Y. An updated meta-analysis of endothelial nitric oxide synthase gene: three well-characterized polymorphisms with hypertension. PLoS One 6, e24266, https://doi.org/10.1371/journal.pone.0024266 (2011).

27. Zhu, Y. et al. The genetic association between iNOS and eNOS polymorphisms and gastric cancer risk: a meta-analysis. Onco Targets Ther 11, 2497-2507, https://doi.org/10.2147/OTT.S161925 (2018).

28. Bayazit, Y. A. et al. Role of nitric oxide synthase gene intron 4 and exon 7 polymorphisms in obstructive sleep apnea syndrome. Eur Arch Otorhinolaryngol 266, 449-454, https://doi.org/10.1007/s00405-008-0763-0 (2009).

29. Nassereddine, S. et al. The polymorphism G894 T of endothelial nitric oxide synthase (eNOS) gene is associated with susceptibility to essential hypertension (EH) in Morocco. BMC Med Genet 19, 127, https://doi.org/10.1186/s12881-018-0638-1 (2018).

30. Yasuda, Y. et al. A functional polymorphism of the GTP cyclohydrolase 1 gene predicts attention performance. Neurosci Lett 566, 46-49, https://doi.org/10.1016/j.neulet.2014.02.019 (2014).

31. Heddini, U. et al. GCH1-polymorphism and pain sensitivity among women with provoked vestibulodynia. Mol Pain 8, 68, https:// doi.org/10.1186/1744-8069-8-68 (2012).

32. Yan, J. T. et al. Polymorphisms of genes in nitric oxide-forming pathway associated with ischemic stroke in Chinese Han population. Acta Pharmacol Sin 32, 1357-1363, https://doi.org/10.1038/aps.2011.114 (2011).

33. Pierola, J. et al. NADPH oxidase p22phox polymorphisms and oxidative stress in patients with obstructive sleep apnoea. Respir Med 105, 1748-1754, https://doi.org/10.1016/j.rmed.2011.08.006 (2011).

34. San Jose, G., Fortuno, A., Beloqui, O., Diez, J. \& Zalba, G. NADPH oxidase CYBA polymorphisms, oxidative stress and cardiovascular diseases. Clin Sci (Lond) 114, 173-182, https://doi.org/10.1042/CS20070130 (2008).

35. Sia, C. H. et al. Awareness and knowledge of obstructive sleep apnea among the general population. Sleep Med 36, 10-17, https://doi. org/10.1016/j.sleep.2017.03.030 (2017).

36. Xia, N. et al. Resveratrol reverses endothelial nitric-oxide synthase uncoupling in apolipoprotein E knockout mice. J Pharmacol Exp Ther 335, 149-154, https://doi.org/10.1124/jpet.110.168724 (2010).

37. Wolkow, P. P. et al. GTP cyclohydrolase I gene polymorphisms are associated with endothelial dysfunction and oxidative stress in patients with type 2 diabetes mellitus. PLoS One 9, e108587, https://doi.org/10.1371/journal.pone.0108587 (2014).

38. Lattimore, J. L., Wilcox, I., Skilton, M., Langenfeld, M. \& Celermajer, D. S. Treatment of obstructive sleep apnoea leads to improved microvascular endothelial function in the systemic circulation. Thorax 61, 491-495, https://doi.org/10.1136/thx.2004.039164 (2006).

39. Badran, M., Golbidi, S., Ayas, N. \& Laher, I. Nitric Oxide Bioavailability in Obstructive Sleep Apnea: Interplay of Asymmetric Dimethylarginine and Free Radicals. Sleep Disord 2015, 387801, https://doi.org/10.1155/2015/387801 (2015).

40. Yuksel, M., Okur, H. K., Pelin, Z., Ogunc, A. V. \& Ozturk, L. Arginase activity and nitric oxide levels in patients with obstructive sleep apnea syndrome. Clinics (Sao Paulo) 69, 247-252, https://doi.org/10.6061/clinics/2014(04)05 (2014). 
41. Bendall, J. K., Douglas, G., McNeill, E., Channon, K. M. \& Crabtree, M. J. Tetrahydrobiopterin in cardiovascular health and disease. Antioxid Redox Signal 20, 3040-3077, https://doi.org/10.1089/ars.2013.5566 (2014).

42. Latremoliere, A. \& Costigan, M. GCH1, BH4 and pain. Curr Pharm Biotechnol 12, 1728-1741 (2011).

43. Tegeder, I. et al. GTP cyclohydrolase and tetrahydrobiopterin regulate pain sensitivity and persistence. Nat Med 12, 1269-1277, https://doi.org/10.1038/nm1490 (2006).

44. Doehring, A., Antoniades, C., Channon, K. M., Tegeder, I. \& Lotsch, J. Clinical genetics of functionally mild non-coding GTP cyclohydrolase 1 (GCH1) polymorphisms modulating pain and cardiovascular risk. Mutat Res 659, 195-201, https://doi. org/10.1016/j.mrrev.2008.04.007 (2008).

45. Lassegue, B. \& Griendling, K. K. NADPH oxidases: functions and pathologies in the vasculature. Arterioscler Thromb Vasc Biol 30, 653-661, https://doi.org/10.1161/ATVBAHA.108.181610 (2010).

46. Wyche, K. E. et al. C242T CYBA polymorphism of the NADPH oxidase is associated with reduced respiratory burst in human neutrophils. Hypertension 43, 1246-1251, https://doi.org/10.1161/01.HYP.0000126579.50711.62 (2004).

47. Cascales, A. et al. Association of anthracycline-related cardiac histological lesions with NADPH oxidase functional polymorphisms. Oncologist 18, 446-453, https://doi.org/10.1634/theoncologist.2012-0239 (2013).

48. Zhou, Y. \& Zhao, Y. C. Association between the nicotinamide adenine dinucleotide phosphate oxidase p22phox gene -A930G polymorphism and intracerebral hemorrhage. Mol Med Rep 11, 3511-3516, https://doi.org/10.3892/mmr.2015.3154 (2015).

49. Qin, Y. W. et al. The A930G polymorphism of 22 phox (CYBA) gene but not C242T variation is associated with hypertension: a meta-analysis. PLoS One 8, e82465, https://doi.org/10.1371/journal.pone.0082465 (2013).

50. Heiss, C., Rodriguez-Mateos, A. \& Kelm, M. Central role of eNOS in the maintenance of endothelial homeostasis. Antioxid Redox Signal 22, 1230-1242, https://doi.org/10.1089/ars.2014.6158 (2015).

51. Huang, P. L. eNOS, metabolic syndrome and cardiovascular disease. Trends Endocrinol Metab 20, 295-302, https://doi.org/10.1016/j. tem.2009.03.005 (2009).

52. Moro, M. A., Cardenas, A., Hurtado, O., Leza, J. C. \& Lizasoain, I. Role of nitric oxide after brain ischaemia. Cell Calcium 36, 265-275, https://doi.org/10.1016/j.ceca.2004.02.011 (2004).

53. Atkeson, A. \& Jelic, S. Mechanisms of endothelial dysfunction in obstructive sleep apnea. Vasc Health Risk Manag 4, 1327-1335, https://doi.org/10.2147/vhrm.s4078 (2008).

54. Gad, M. Z. et al. Endothelial nitric oxide synthase (G894T) gene polymorphism in a random sample of the Egyptian population: comparison with myocardial infarction patients. Genet Test Mol Biomarkers 16, 695-700, https://doi.org/10.1089/gtmb.2011.0342 (2012).

55. Chatsuriyawong, S. et al. Polymorphisms in nitric oxide synthase and endothelin genes among children with obstructive sleep apnea. BMC Med Genomics 6, 29, https://doi.org/10.1186/1755-8794-6-29 (2013).

56. Seckin, Y. et al. Association of eNOS Gene Polymorphisms G894T and T-786C with Risk of Hepatorenal Syndrome. Gastroenterol Res Pract 2016, 2579626, https://doi.org/10.1155/2016/2579626 (2016).

57. El-Lebedy, D. Interaction between endothelial nitric oxide synthase rs1799983, cholesteryl ester-transfer protein rs708272 and angiopoietin-like protein 8 rs2278426 gene variants highly elevates the risk of type 2 diabetes mellitus and cardiovascular disease. Cardiovasc Diabetol 17, 97, https://doi.org/10.1186/s12933-018-0742-8 (2018).

58. Sleep-related breathing disorders in adults: recommendations for syndrome definition and measurement techniques in clinical research. The Report of an American Academy of Sleep Medicine Task Force. Sleep 22, 667-689 (1999).

59. Chung, F., Abdullah, H. R. \& Liao, P. STOP-Bang Questionnaire: A Practical Approach to Screen for Obstructive Sleep Apnea. Chest 149, 631-638, https://doi.org/10.1378/chest.15-0903 (2016).

60. Johns, M. W. A new method for measuring daytime sleepiness: the Epworth sleepiness scale. Sleep 14, 540-545, https://doi. org/10.1093/sleep/14.6.540 (1991).

\section{Acknowledgements}

This study was supported by Tehran University of Medical Sciences. The authors would like to express their thanks to Dr Solmaz Arshi at Occupational Sleep Research Center of Baharloo Hospital and Dr Samaneh Akbarpour at Clinical Research Development Unit (CRDU) of Baharloo Hospital, and they would also like to thank Occupational Sleep Research Center and Sleep Clinic of Imam Khomeini Hospitals, Tehran University of Medical Sciences, Tehran, Iran for their support, cooperation, and helps throughout the study. The authors express special thanks to Yekta Lab personnel for their kind assistance in the process of research. We appreciate Dr. Abdolkarim Hosseini for his kind help, as a research assistant.

\section{Author contributions}

M.B. and Y.S. designed the experiments, S.S.K. carried out the experiments, Y.S. contributed in molecular experiments, K.S. performed patient's polysomnography analysis, S.S.K. and Y.S. conducted the data analysis, and all the authors wrote and edit the final manuscript.

\section{Competing interests}

The authors declare no competing interests.

\section{Additional information}

Correspondence and requests for materials should be addressed to M.B.

Reprints and permissions information is available at www.nature.com/reprints.

Publisher's note Springer Nature remains neutral with regard to jurisdictional claims in published maps and institutional affiliations.

Open Access This article is licensed under a Creative Commons Attribution 4.0 International License, which permits use, sharing, adaptation, distribution and reproduction in any medium or format, as long as you give appropriate credit to the original author(s) and the source, provide a link to the Creative Commons license, and indicate if changes were made. The images or other third party material in this article are included in the article's Creative Commons license, unless indicated otherwise in a credit line to the material. If material is not included in the article's Creative Commons license and your intended use is not permitted by statutory regulation or exceeds the permitted use, you will need to obtain permission directly from the copyright holder. To view a copy of this license, visit http://creativecommons.org/licenses/by/4.0/.

(C) The Author(s) 2019 